\title{
PEMANFAATAN MODEL PEMBELAJARAN KOOPERATIF TIPE JIGSAW UNTUK MENINGKATKAN PEMAHAMAN MAHASISWA S1 PGSD UNIROW TENTANG MODEL-MODEL PEMBELAJARAN TERPADU PADA MATA KULIAH PEMBELAJARAN TEMATIS
}

\author{
Wendri Wiratsiwi \\ Fakultas Keguruan Ilmu Pendidikan, Unirow \\ Email: wendriwiratsiwi3489@gmail.com
}

\begin{abstract}
Abstrak: Tujuan penelitian ini adalah meningkatkan pemahaman belajar mahasiswa PGSD Unirow semester IV tahun akademik 2015/2016 tentang model-model pembelajaran terpadu pada mata kuliah Pembelajaran Tematis dengan pemanfaatan model pembelajaran kooperatif tipe Jigsaw. Penelitian ini menggunakan jenis penelitian tindakan kelas. Hasil penelitian ini menunjukkan bahwa pemanfaatan model pembelajaran kooperatif tipe Jigsaw pada materi model-model pembelajaran terpadu dapat meningkatkan pemahaman belajar mahasiswa PGSD Unirow semester IV tahun akademik 2015/2016 pada matakuliah Pembelajaran Tematis. Hal tersebut terefleksi dari beberapa indikator: 1) aktivitas mahasiswa selama pemanfaatan model Jigsaw mencapai keberhasilan dengan persentase keberhasilan $66,11 \%$ pada siklus I dan 90,93\% pada siklus II ; 2) aktivitas dosen selama pemanfaatan model Jigsaw mencapai keberhasilan dengan persentase keberhasilan $68,45 \%$ pada siklus I dan 95,24\% pada siklus II; 3) ketuntasan klasikal mencapai keberhasilan dengan persentase $75 \%$ pada siklus I menjadi $86,11 \%$ pada siklus II. Dengan demikian dapat disimpulkan bahwa model pembelajaran kooperatif tipe jigsaw dapat meningkatkan pemahaman belajar mahasiswa PGSD Unirow semester IV tahun akademik 2015/2016 tentang model-model pembelajaran terpadu pada mata kuliah pembelajaran tematis.
\end{abstract}

Kata kunci: Model pembelajaran kooperatif tipe Jigsaw, pemahaman belajar, model-model pembelajaran terpadu

\begin{abstract}
The purpose of this research to improve understanding of learning for fourth students at Unirow primary teacher education in 2015/2016 academic year abaut integrated learning models of Thematic subject learning use Jigsaw cooperative models. The methode of research is classroom action research. The results of this research show that using jigsaw cooperative models on integrated learning models can improve understanding of learning to PGSD Unirow fourth students at Unirow primary teacher education in 2015/2016 academic year in Thematic Learning. This is reflected in some indicators 1) Student activity during use jigsaw cooperative models achieve success with success percentage $66.11 \%$ in the first cycle and $90.93 \%$ in the second cycle; 2) the activity of lecturers during the use jigsaw cooperative models achieve success with success percentage $68.45 \%$ in the first cycle and $95.24 \%$ in the second cycle; 3) classical completeness achieve success with success percentage $75 \%$ in the first cycle to $86.11 \%$ in the second cycle. It can be concluded that the jigsaw cooperative model can improve understanding of learning student for fourth students at Unirow primary teacher education in 2015/2016 academic year abaut integrated learning models of Thematic subject learning.
\end{abstract}

Keywords: Jigsaw cooperative models, understanding of learning, integrated learning models 


\section{PENDAHULUAN}

Kesuksesan proses pembelajaran dalam suatu kelas faktor utamanya bergantung pada pengetahuan dan keterampilan dosen dalam melaksanakan pembelajaran. Karena keberadaan kelas, dosen, mahasiswa, dan model pembelajaran harus sesuai seperti apa yang direncanakan dosen tersebut. Banyak cara yang dilakukan oleh dosen untuk proses pembelajarannya yang semuanya bertujuan untuk meningkatkan kualitas dan kuantitas proses pembelajaran tersebut. Terjadinya interaksi yang baik antara dosen dengan mahasiswa di kelas akan mempengaruhi keaktifan siswa di kelas. Anderson (1989:9) menyatakan "the quality of the relationship between teacher and student has an impact on the student's willingness to participate in the classroom". Pada pelaksanaan suatu proses belajar mengajar terdapat kegiatan belajar yang dilakukan oleh mahasiswa dan mengajar yang dilakukan oleh dosen.

Kegiatan belajar yang dilakukan mahasiswa bukan hanya yang penting belajar, tapi bagaimana proses belajar yang telah dilakukan dapat meninggalkan kesan dan tidak terlupakan begitu saja dengan kata lain dapat memberikan pengalaman belajar yang bermakna (meaningful learning). Sebagaimana dikatakan bahwa "belajar merupakan suatu proses, suatu kegiatan dan bukan hasil atau tujuan"(Hamalik, 2008:36). Selanjutnya, belajar diartikan sebagai proses perubahan tingkah laku pada diri individu berkat adanya interaksi antara individu dan individu dengan lingkungannya" (Usman, 2006:5). Perubahan tingkah laku relatif menetap dan dapat terjadi berkat latihan dan pengalaman (Hamalik, 2008:154).

Salah satu tujuan tujuan pendidikan melalui proses pembelajaran antara lain menanamkan pengetahuan dan pemahaman pada siswa sesuai dengan kebutuhan. Dalam proses pembelajaran, mahasiswa PGSD dituntut untuk dapat memiliki pemahaman dan pengetahuan pada berbagai mata kuliah guna mempersiapkan diri untuk menjadi calon guru SD yang profesional.

Berkaitan dengan tujuan pembelajaran pada mahasiswa PGSD yaitu menanamkan pengetahuan dan pemahaman terhadap berbagai mata kuliah guna mempersiapkan diri untuk menjadi calon guru SD yang profesional, maka mahasiswa PGSD dituntut untuk memiliki pengetahuan dan pemahaman salah satunya pada mata kuliah pembelajaran tematis. Salah satu kompetensi yang harus dicapai dalam mata kuliah tersebut adalah memahami ragam model pembelajaran terpadu.

Berdasarkan hasil observasi terhadap kegiatan pembelajaran pada kompetensi memahami ragam model pembelajaran terpadu, diperoleh informasi bahwa; 1) Sebagian besar mahasiswa masih belum memahami konsep tentang ragam model pembelajaran terpadu karena mahasiswa cenderung menghafal beberapa jenis model pembelajaran terpadu yang sudah biasa diterapkan; 2) Dosen masih mengajar dengan model konvensional yakni memakai metode ceramah. Pada dasarnya metode ceramah bisa diterapkan dalam pembelajaran tematis, namun penggunaan metode ini mengakibatkan kurangnya keaktifan mahasiswa karena dosen lebih mendominasi dalam pembelajaran sehingga mengakibatkan mahasiswa kurang tertarik dengan pembelajaran yang dilaksanakan; 3) Hasil belajar mahasiswa PGSD semester IV untuk mata kuliah pembelajaran tematis pada kompetensi ragam model pembelajaran terpadu masih tergolong rendah. Hal ini dapat dibuktikan bahwa nilai Ulangan 
Tengah Semester IV tahun akademik 2015/2016 sebelum adanya perbaikan, siswa yang tuntas atau mencapai kriteria ketuntasan minimal (KKM) adalah $44,4 \%$ siswa. Siswa yang belum mencapai kriteria ketuntasan minimal (KKM) adalah $55,6 \%$ mahasiswa.

Memperhatikan

permasalahanpermasalahan yang terjadi khususnya pada mahasiswa dan dosen pada mata kuliah pembelajaran tematis, maka perlu dicari suatu model pembelajaran yang efektif untuk meningkatkan pemahaman mahasiswa pada kompetensi memahami ragam model pembelajaran terpadu. Oleh karena itu peneliti ingin memberikan solusi dengan menggunakan model pembelajaran kooperatif tipe Jigsaw.

Model pembelajaran kooperatif tipe Jigsaw merupakan model pembelajaran kooperatif, dengan mahasiswa dalam kelompok kecil yang terdiri dari 4-6 orang secara heterogen dan bekerjasama saling ketergantungan yang positif dan bertanggung jawab atas ketuntasan bagian materi pembelajaran yang harus dipelajari dan menyampaikan materi tersebut kepada anggota kelompok yang lain

Pembelajaran kooperatif tipe Jigsaw diperkenalkan oleh Elliot Aronson. Menurut Arends (dalam Amri \& Ahmadi, 2010: 94), pembelajaran kooperatif tipe Jigsaw adalah tipe pembelajaran kooperatif yang terdiri dari beberapa anggota dalam satu kelompok yang bertanggung jawab atas penguasaan bagian materi belajar dan mampu mengajarkan materi tersebut kepada anggota lain dalam kelompoknya. Menurut Isjoni (2007: 54) pembelajaran kooperatif jigsaw adalah salah satu tipe pembelajaran kooperatif yang mendorong peserta didik aktif dan saling bekerja sama dalam menguasai materi pelajaran untuk mencapai prestasi yang maksimal.
Karakteristik dari model pembelajaran kooperatif tipe jigsaw yaitu terdiri dari 2 kelompok yang dinamakan kelompok asal dan kelompok ahli. Kelompok asal yaitu kelompok induk siswa yang beranggotakan mahasiswa dengan kemampuan, asal, latar belakang keluarga yang beragam. Kelompok ahli adalah kelompok mahasiswa yang terdiri dari anggota kelompok asal yang berbeda untuk mempelajari dan mendalami topik tertentu sebagai tugasnya dan kemudian dijelaskan kepada kelompok asal.

Model pembelajaran kooperatif tipe jigsaw didesain untuk meningkatkan rasa tanggung jawab mahasiswa terhadap materi pembelajarannya sendiri dan juga materi pembelajaran yang diberikan orang lain. Mahasiswa tidak hanya mempelajari materi yang diberikan, tetapi mereka juga harus siap memberikan dan mengajarkan materi tersebut pada anggota kelompoknya yang lain. Dengan demikian, mahasiswa saling tergantung satu dengan yang lain dan harus bekerja sama secara kooperatif untuk mempelajari materi yang ditugaskan. Melalui pembelajaran kooperatif mahasiswa dapat berinteraksi secara aktif dan positif dalam diskusi kelompok. Hal ini sangat memberikan kesempatan bagi peserta didik untuk mengolah informasi dan kemudian mengkomunikasikannya sehingga dapat meningkatkan pemahaman mahasiswa terhadap materi yang disampaikan.

Pada pelaksanaan proses belajar mengajar, hal terpenting adalah pencapaian dari tujuan pembelajaran itu sendiri, yaitu agar mahasiswa mampu memahami sesuatu berdasarkan pengalaman belajarnya. Pemahaman berasal dari kata "paham" yang berarti mengerti benar, tahu benar, pandai dan mengerti benar tentang sesuatu hal. Pemahaman adalah proses, perbuatan, cara memahami (Fajri, 2008:608). Sehingga dapat diartikan bahwa pemahaman adalah suatu 
proses, cara memahami, cara mempelajari baik-baik supaya paham dan pengetahuannya banyak. Sedangkan menurut Hamalik (2003:48), pemahaman adalah kemampuan melihat hubungan hubungan antara berbagai faktor atau unsur dalam situasi yang problematis. Sedangkan menurut Mulyasa (2005:78) menyatakan bahwa pemahaman adalah kedalaman kognitif dan afektif yang dimiliki oleh individu.

Arikunto (2009:118) menyatakan bahwa pemahaman (comprehension) adalah bagaimana seorang mempertahankan, membedakan, menduga (estimates), menerangkan, memperluas, menyimpulkan, menggeneralisasikan, memberikan contoh, menuliskan kembali, dan memperkirakan. Dengan pemahaman, mahasiswa diminta untuk membuktikan bahwa ia memahami hubungan yang sederhana di antara faktafakta atau konsep.

\section{METODE}

Penelitian ini menggunakan metode Penelitian Tindakan Kelas (PTK). PTK adalah penelitian yang bertujuan untuk meningkatkan kualitas proses dan hasil pembelajaran di kelas, atau memecahkan masalah pembelajaran di kelas/ di latar penelitian yang dilakukan secara bersiklus.

Model pelaksanaan PTK ini menggunakan model PTK "guru sebagai peneliti" dengan acuan model siklus PTK yang dikembangkan oleh Arikunto (dalam Suyadi, 2010:49), dengan digambarkan sebagai berikut:

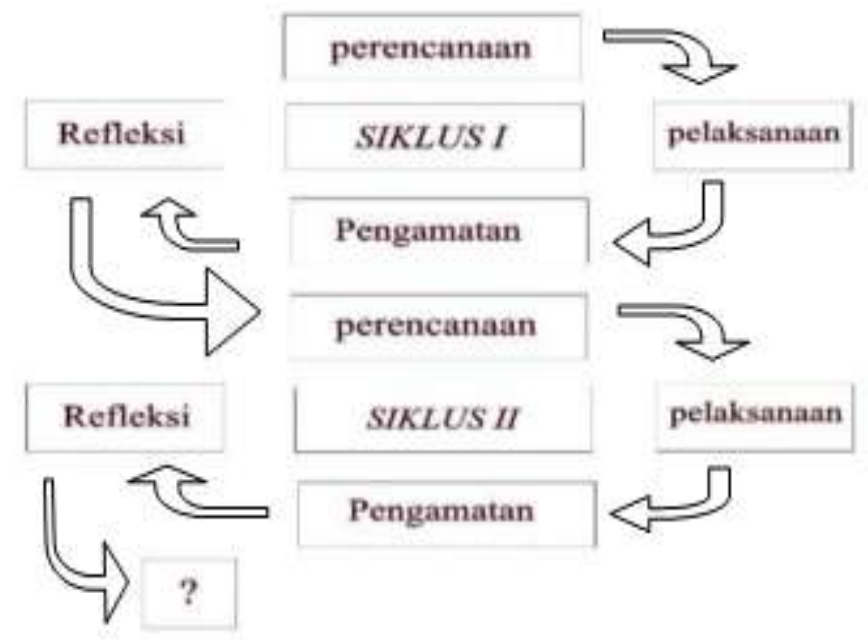

\section{Bagan 1. Bagan Siklus PTK}

Dari rancangan model PTK di atas menunjukkan bahwa PTK dapat dilaksanakan dalam beberapa siklus, dan setiap siklus terdiri dari empat tahap, yaitu: a). perencanaan; b). pelaksanaan tindakan; c). observasi; dan d). refleksi. Penelitian tindakan kelas ini dilakukan di tahun akademik 2015/2016 pada mahasiswa PGSD Unirow semester IV.

\section{Teknik Pengumpulan Data}

Teknik pengumpulan data dalam penelitian ini adalah tes, observasi, dan wawancara.

a. Tes

Tes adalah serentetan pertanyaan atau latihan serta alat lain yang digunakan untuk mengukur keterampilan, pengetahuan, intelegensi, kemampuan, atau bakat yang dimiliki oleh individu atau kelompok (Arikunto, 2006:150). 
Tes dilakukan secara tertulis dengan bentuk uraian. Tes ini dilakukan untuk mendapatkan data hasil belajar mahasiswa untuk mengukur pemahaman belajar setelah mengikuti proses pembelajaran dengan menerapkan model pembelajaran kooperatif tipe jigsaw.

b. Observasi

Teknik pengamatan atau observasi dilakukan untuk mengumpulkan data tentang aktivitas mahasiswa dan dosen selama proses pembelajaran berlangsung.

\section{Instrumen Pengumpulan Data}

Instrumen pengumpulan data dalam penelitian ini adalah lembar tes dan lembar observasi.

a. Lembar Tes

Tes ini berupa tes tulis yang dilakukan secara individu yang hasilnya nanti akan digunakan sebagai acuan untuk mengetahui tingkat ketercapaian hasil belajar mahasiswa untuk mengukur pemahaman mahasiswa.

b. Lembar Observasi

Lembar observasi ini digunakan untuk mengamati kejadian yang berlangsung selama proses pembelajaran (observasi aktivitas mahasiswa dan dosen).

\section{Teknik Analisis Data}

Analisis data merupakan salah satu langkah penting dalam penelitian dalam rangka memperoleh temuan-temuan hasil penelitian. Hasil pengumpulan data perlu diadakan pengolahan data atau analisis data. Dalam menganalisis data seorang peneliti harus mampu menentukan dengan tepat metode analisis mana yang akan digunakan. Teknik analisis data yang digunakan yaitu:

a. Data Tes

Data yang diperoleh selama penelitian melalui tes untuk mengetahui pemahaman mahasiswa akan dianalisis dengan menggunakan rumus:

1) Rata-rata kelas

$$
\begin{aligned}
& \mathrm{X}=\frac{\sum x i}{\mathrm{n}} \\
& \text { Keterangan : } \\
& \mathrm{X} \quad=\text { Rata-rata kelas } \\
& \quad \sum x i \quad=\text { Jumlah nilai }
\end{aligned}
$$

seluruh siswa

$$
\mathrm{n} \quad=\text { Jumlah seluruh siswa }
$$

2) Ketuntasan belajar

$$
P=\frac{\mathrm{n}}{\mathrm{N}} \times 100 \%
$$

Keterangan:

$\mathrm{P}=$ Persentase ketuntasan

$\mathrm{N}=$ Jumlah frekuensi yang tuntas belajar

$\mathrm{n}=$ Jumlah seluruh siswa (Arikunto, 2008:118)

b. Data hasil observasi

Data yang diperoleh selama penelitian melalui observasi yang banyak dilakukan oleh aktivitas guru dan siswa akan dianalisis dengan menggunakan rumus:

$$
P=\frac{\mathrm{f}}{\mathrm{N}} \times 100 \%
$$

Keterangan:

$\mathrm{f}=$ Jumlah skor yang akan dipersentasikan

$\mathrm{N}=$ Jumlah skor maksimal semua komponen yang diambil

$\mathrm{P}=$ Angka persentase

Kriteria penilaian

$80 \%-100 \%=$ baik sekali

$66 \%-79 \%=$ baik

$56 \%-65 \%=$ cukup

$40 \%-55 \%=$ kurang

$0 \%-39 \%=$ gagal

Penelitian ini dikatakan berhasil jika:

a. Persentase keseluruhan aktivitas mahasiswa dalam kegiatan pembelajaran mencapai keberhasilan $\geq 85 \%$.

b. Persentase aktivitas dosen dalam kegiatan pembelajaran mencapai keberhasilan $\geq$ $85 \%$. 
c. Persentase ketuntasan belajar siswa secara mencapai $85 \%$. individu $\geq 65$ dan secara klasikal

\section{HASIL DAN PEMBAHASAN}

Tabel 1. Data Hasil Aktivitas Mahasiswa siklus I-II

\begin{tabular}{|c|c|c|c|}
\hline \multirow{2}{*}{ No } & \multirow{2}{*}{ Aspek yang Diamati } & \multicolumn{2}{|c|}{$\begin{array}{l}\text { (\%) Persentase } \\
\text { Keberhasilan }\end{array}$} \\
\hline & & $\begin{array}{l}\text { Siklus } \\
\text { I }\end{array}$ & $\begin{array}{l}\text { Siklus } \\
\text { II }\end{array}$ \\
\hline 1 & Memperhatikan penjelasan guru & 64,81 & 88,89 \\
\hline 2 & Melaksanakan diskusi kelompok & 56,48 & 90,74 \\
\hline 3 & $\begin{array}{l}\text { Kerja sama dalam mengerjakan } \\
\text { tugas kelompok }\end{array}$ & 64,81 & 88,89 \\
\hline 4 & Menjawab kuis & 74,07 & 89,81 \\
\hline 5 & Mengerjakan soal evaluasi & 70,37 & 96,30 \\
\hline & $\sum$ (Jumlah) & 330,54 & 454,63 \\
\hline & (\%) Persentase & 66,11 & 90,93 \\
\hline
\end{tabular}

Berdasarkan Tabel 1 di atas, dapat dilihat bahwa aktivitas mahasiswa selama pembelajaran dengan memanfaatkan model kooperatif tipe jigsaw mengalami peningkatan dari siklus I hingga siklus II.

Rata-rata persentase keberhasilan aspek 1 yaitu tentang memperhatikan penjelasan guru, yang dicapai pada siklus I adalah $56,48 \%$ dan rata-rata persentase keberhasilan pada siklus II adalah $88,89 \%$ (terjadi peningkatan $24,08 \%$ dari siklus I).

Rata-rata persentase keberhasilan aspek 2 yaitu tentang melaksanakan diskusi kelompok, yang dicapai pada siklus I adalah $56,48 \%$ dan rata-rata persentase keberhasilan pada siklus II adalah 90,74\% (terjadi peningkatan $35,88 \%$ dari siklus I).

Rata-rata persentase keberhasilan aspek 3 yaitu tentang kerja sama dalam melaksanakan tugas kelompok yang dicapai pada siklus I adalah $64,81 \%$ dan rata-rata persentase keberhasilan pada siklus II adalah $88,89 \%$ (terjadi peningkatan $24,08 \%$ dari siklus I).

Rata-rata persentase keberhasilan aspek 4 yaitu tentang menjawab kuis yang dicapai pada siklus I adalah $74,07 \%$ dan rata-rata persentase keberhasilan pada siklus II adalah $89,81 \%$ (terjadi peningkatan $15,74 \%$ dari siklus I).

Rata-rata persentase keberhasilan aspek 5 yaitu tentang mengerjakan soal evaluasi yang dicapai pada siklus I adalah $70,37 \%$ dan ratarata persentase keberhasilan pada siklus II adalah $96,03 \%$ (terjadi peningkatan $25,66 \%$ dari siklus I).

Tabel 2. Data Hasil Aktivitas Dosen siklus I-II

\begin{tabular}{|c|l|c|c|}
\hline \multirow{2}{*}{ No } & \multicolumn{1}{|c|}{ Aspek yang Diamati } & \multicolumn{2}{c|}{$\begin{array}{c}\text { Ke Persentase } \\
\text { Keberhasilan }\end{array}$} \\
\cline { 3 - 4 } & & Siklus I & Siklus II \\
\hline 1 & Memotivasi mahasiswa/ memberi apersepsi & 66,67 & 100 \\
\hline 2 & Menyampaikan tujuan pembelajaran & 58,33 & 83,33 \\
\hline 3 & Membentuk kelompok belajar mahasiswa (kelompok asal) & 100 & 100 \\
\hline 4 & Menyajikan materi pelajaran & 50 & 100 \\
\hline 5 & Membagi teks konsep materi & 100 & 100 \\
\hline 6 & Meminta mahasiswa membaca teks konsep yang didapat & 50 & 83,33 \\
\hline 7 & Membentuk kelompok ahli & 66,67 & 100 \\
\hline 8 & Membimbing tugas mengajar pada kelompok asal & 58,33 & 100 \\
\hline
\end{tabular}




\begin{tabular}{|c|l|c|c|}
\hline \multirow{2}{*}{ No } & \multicolumn{2}{|c|}{ Aspek yang Diamati } & \multicolumn{2}{c|}{$\begin{array}{c}\text { \%) Persentase } \\
\text { Keberhasilan }\end{array}$} \\
\cline { 3 - 4 } & & Siklus I & Siklus II \\
\hline 9 & Membimbing diskusi menyelesaikan tugas & 75 & 100 \\
\hline 10 & Memberi kuis pada mahasiswa & 83,33 & 83,33 \\
\hline 11 & Memberi penghargaan kepada kelompok & 66,67 & 100 \\
\hline 12 & Mempertegas hasil diskusi mahasiswa & 33,33 & 83,33 \\
\hline 13 & Memberikan soal evaluasi & 100 & 100 \\
\hline 14 & Menyimpulkan materi ajar & 50 & 100 \\
\hline \multicolumn{2}{|c|}{$($ (J) Persentase } & 958,33 & 1333,32 \\
\hline \multicolumn{2}{|c|}{} & 68,45 & 95,24 \\
\hline
\end{tabular}

Berdasarkan Tabel 2 di atas, dapat dilihat bahwa kemampuan dosen dalam menyampaikan pembelajaran kooperatif tipe jigsaw mengalami peningkatan dari siklus I hingga siklus II. Pada proses pembelajaran siklus I, dosen belum mencapai target penyampaian proses pembelajaran yang telah ditentukan, walaupun demikian dosen menyampaikan proses pembelajaran dengan baik dan tingkat keberhasilan dalam menyampaikam proses pembelajaran adalah sebesar $68,45 \%$. Sedangkan pada siklus II, dengan sangat baik guru menyampaikan proses pembelajaran kooperatif tipe jigsaw dengan persentase sebesar 95,24\%. Hal ini menunjukkan peningkatan sebesar 26,79\% dari pada proses pembelajaran pada siklus I, dan guru telah mencapai target penyampaian proses pembelajaran.

Tabel 3. Data Hasil Belajar Mahasiswa siklus I-II

\begin{tabular}{|l|l|c|c|c|}
\hline No & Nama Siswa & Observasi Awal & Siklus I & Siklus II \\
\hline 1 & Deni S & 48 & 53,8 & 65,4 \\
\hline 2 & Sodik & 60 & 50 & 50 \\
\hline 3 & Junadi & 48 & 34,6 & 42,3 \\
\hline 4 & Rumiati & 55 & 65,4 & 65,4 \\
\hline 5 & Edi Kasminto & 48 & 65,4 & 76,9 \\
\hline 6 & Nur Hakim & 34 & 69,2 & 80,8 \\
\hline 7 & Santi & 60 & 53,8 & 65,4 \\
\hline 8 & Siti Komariah & 65 & 46,1 & 76,9 \\
\hline 9 & Sofia Listiyo Wati & 80 & 53,8 & 69,2 \\
\hline 10 & Esterni & 48 & 84,6 & 65,4 \\
\hline 11 & Giarto & 55 & 73,1 & 73,1 \\
\hline 12 & Jiyanti Artana Gini & 34 & 34,6 & 80,8 \\
\hline 13 & Yanto & 74 & 69,2 & 84,6 \\
\hline 14 & Abdul Rais & 80 & 76,9 & 88,5 \\
\hline 15 & Khozin & 55 & 65,4 & 80,8 \\
\hline 16 & Anang & 34 & 53,8 & 42,3 \\
\hline 17 & Andy Gunawan & 55 & 65,4 & 50 \\
\hline 18 & Arif & 80 & 88,5 & 84,6 \\
\hline 19 & Dea Rizky Lorenza & 55 & 65,4 & 69,2 \\
\hline 20 & Fatatin Hilda Nosita & 87 & 73,1 & 84,6 \\
\hline 21 & Karista Dwianti & 65 & 73,1 & 65,4 \\
\hline 22 & Dion & M. Choirul Huda & 80,8 & 57,6 \\
\hline 23 & Mochamad Rifqi & & 5,1 \\
\hline 24 & & & \\
\hline
\end{tabular}




\begin{tabular}{|c|l|c|c|c|}
\hline No & Nama Siswa & Observasi Awal & Siklus I & Siklus II \\
\hline 25 & M. Abdul Rohman & 87 & 84,6 & 88,5 \\
\hline 26 & M. Abdul Rochim & 70 & 65,4 & 96,1 \\
\hline 27 & Dony & 55 & 65,4 & 76,9 \\
\hline 28 & Nurul Huda & 65 & 73,1 & 65,4 \\
\hline 29 & Qiqi Nur Hidayah & 87 & 88,5 & 76,9 \\
\hline 30 & Sofi Ali Inzha & 48 & 65,4 & 69,2 \\
\hline 31 & Susanti Diah Saputri & 74 & 53,8 & 69,2 \\
\hline 32 & Tandry Ardiansya & 65 & 65,4 & 73,1 \\
\hline 33 & Rudi & 55 & 80,8 & 76,9 \\
\hline 34 & Wibia Kharis Sholikin & 70 & 73,1 & 92,3 \\
\hline 35 & Choirul Nizam & 55 & 65,4 & 76,9 \\
\hline 36 & Ayu Sinta Wati & 60 & 84,6 & 88,5 \\
\hline Jumlah & 2187 & 2415,3 & 2623,1 \\
\hline Rata-rata & 60,75 & 67,09 & 72,86 \\
\hline Jumlah Siswa Tuntas & 16 & 27 & 31 \\
\hline (\%) Persentase Ketuntasan Klasikal & 44,44 & 75 & 86,11 \\
\hline
\end{tabular}

Dari Tabel 3 di atas, dapat dilihat bahwa pada observasi awal rata-rata skor yang dicapai adalah 60,75 dengan ketuntasan klasikal sebesar $44,44 \%$. Setelah diterapkannya pembelajaran kooperatif tipe jigsaw pada pembelajaran siklus I, rata-rata skor yang dicapai mahasiswa adalah 67,09 dan ketuntasan klasikal yang dicapai adalah 75\%. Pada pembelajaran kooperatif tipe jigsaw siklus II rata-rata nilai yang dicapai siswa adalah 72,86 dan ketuntasan klasikal yang dicapai adalah $86,11 \%$.

\section{SIMPULAN DAN SARAN}

\section{Simpulan}

a. Peningkatan aktivitas mahasiswa selama pemanfaatan model pembelajaran kooperatif tipe jigsaw pada siklus I secara keseluruhan mencapai persentase $66,11 \%$. Pada siklus II mencapai persentase 90,93\% (mengalami peningkatan sebesar 24,82\%).

b. Peningkatan aktivitas dosen selama pemanfaatan model pembelajaran kooperatif tipe jigsaw pada siklus I secara klasikal mencapai prosentase $68,45 \%$. Pada siklus II mencapai 95,24\% (mengalami peningkatan sebesar 26,79\%). c. Hasil belajar mahasiswa sebelum memanfaatkan model pembelajaran kooperatif tipe jigsaw sebesar 44,44\%. Setelah memanfaatkan model pembelajaran kooperatif tipe jigsaw hasil belajar siswa pada siklus I mencapai $75 \%$. Pada siklus II mencapai $86,11 \% \quad$ (mengalami peningkatan sebesar $26,79 \%$ ).

\section{Saran}

Memperhatikan hasil penelitian yang telah dilaksanakan agar kemampuan siswa dalam berdiskusi dalam kelompok dapat ditingkatkan, maka penulis memberikan saran-saran sebagai berikut :

a. Sebaiknya model pembelajaran kooperatif tipe jigsaw digunakan dosen dalam proses perkuliahan terutama untuk meningkatkan pemahaman mahasiswa pada mata kuliah yang lain.

b. Dalam menerapkan model pembelajaran kooperatif tipe jigsaw dosen hendaknya memperhatikan pembagian kelompok yang heterogen agar dapat terjalin kerjasama antar siswa

c. Dalam menerapkan model pembelajaran kooperatif tipe jigsaw dosen perlu menjelaskan cara kerja dalam kelompok asal maupun kelompok ahli agar dalam mengikuti pembelajaran mahasiswa 
terarah dengan tugasnya dalam kelompok asal maupun kelompok ahli.

\section{DAFTAR PUSTAKA}

Amri, S. \& Ahmadi, L. K. 2010. Kontruksi Pengembangan Pembelajaran. Jakarta: Prestasi Pustakaraya.

Anderson, L.W. 1989. The effective teacher. New York: McGraw-Hill,Inc.

Arikunto, S. 2006. Prosedur Penelitian Suatu Pendekatan Praktik. Jakarta: Rineka Cipta.

----------. 2009. Dasar-dasar Evaluasi Pendidikan. Jakarta: Rineka Cipta.

Fajri, E. \& Ratu A. S. 2008. Kamus Lengkap Bahasa Indonesia. Jakarta:Difa Publisher.

Hamalik, O. 2003. Kurikulum dan Pembelajaran. Jakarta: PT Bumi Aksara.

--------. (2008). Evaluasi kurikulum. Bandung : PT. Remaja Rosdakarya.

Isjoni. 2007. Cooperatif Learning. Pekanbaru: Alfabeta

Mulyasa, E. 2005. Menjadi Guru Profesional. Bandung:PT. Remaja Rosdakarya

Suyadi. 2010. Panduan Penelitian Tindakan Kelas Buku Panduan Wajib Bagi Para Pendidik. Jogjakarta: Diva Press.

Usman, M. (2006). Menjadi guru profesional. Bandung: PT. Remaja Rosdakarya. 